\title{
Bonding across Chinese social media
}

\section{The pragmatics of language play in “精 (sang) 彩 (xin) 有 (bing) 趣 (kuang)” construction}

\author{
Chaoqun Xie, Ying Tong ${ }^{2,3}$ and Francisco Yus ${ }^{4}$ \\ ${ }^{1}$ Zhejiang International Studies University $\mid{ }^{2}$ Fujian Normal University \\ ${ }^{3}$ Nanjing Xiaozhuang University $\mid{ }^{4}$ University of Alicante
}

This paper explores social bonding in language play via the construction of 'Chinese character (annotation)' on two major social media platforms (Sina Weibo and WeChat) in China. The Chinese characters and their bracketed annotations under study, despite their one-to-one matching in sequence, never match each other either in meaning or in pronunciation. They convey a sense of playfulness among social media users who may be acquaintances or strangers to each other. While research on language play has uncovered systematic interpersonal meanings and social functions, our analysis of screen-based and user-based data shows that such linguistic behavior in a virtual community of practice contributes to social bonding among social media players. Within such structure and with different substitutes for both characters and annotations, social media users frame their expressions in evaluative or emotive ways to facilitate their presentation of an alternative self and of individual or community values.

Keywords: Chinese social media, social bonding, language play, pinyin, virtual community of practice, frames, identity, self, values

\section{Introduction}

Any "local manipulation of elements and relations of language, creative of a specialized genre, code-variety, and/or style" (Kirshenblatt-Gimblett and Sherzer $1976,1)$ can be regarded as language play, which may manifest not only users' creativity and linguistic mastership, but also their ratified or unratified participation status (Maíz-Arévalo 2017). As such, language play has sparked scholarly interest from multiple disciplines in both online and offline communication (cf. Knospe et al. 2016; Bell 2017). Thaler's (2016) review of the established functions 
of language play prior to computer-mediated communication (henceforth CMC) is of much reference value: affectively, language play provokes emotional involvement for its effect of aesthetic pleasure; relationally, it can gain other people's approval by way of amusement and humor, thus creating in-group solidarity. Furthermore, language play can serve to maintain social stability through insinuating various social taboos, and to motivate language learning (Thaler 2016, 51ff and the references therein). To a large extent, language play in CMC can also achieve the above-mentioned offline pragmatic functions through the linguistic devices typically found in text-based CMC (cf. Seargeant and Tagg 2014).

This paper intends to explore such functions through the lens of a typical language play in Chinese social media, whose pragmatic effects may go beyond the positive emotion of mirth, as conversational humor does. The meta-structure of the language play is 'Chinese character (annotation)', where the 'annotation' is used in an analogous way to reflect its literal function, "to add a short explanation or opinion to a text or drawing" (Cambridge English Dictionary), as well as its heterogeneous forms particularly found in our data, covering both pinyin ${ }^{1}$ and Chinese characters, with pinyin symbols being the major form of such online presentation.

This language play catches our attention because such form of annotation is not expected in any style of Chinese writing, yet it is often used in social media. Also, putting annotations in close proximity to the Chinese characters has a potential to sabotage the desired fluidity of the message concerned. More specifically, when in use, pinyin symbols in this structure do not reflect their normal function: they seldom indicate the proper pronunciation of their adjacent Chinese characters. Instead, they often represent other characters whose connotations may deviate dramatically from the original text, as the screenshot in Figure 1 (Example 1) illustrates:

Example 1. The whole microblog reads:

狗狗也冲浪? 还比赛! 加州更多精 (sang) 彩 (xin) 有 (bing) 趣 (kuang) 的节日, 来櫂 $\rightarrow$ 网页链接

The dog is surfing? Even competing! For more information on this fascinating (insane) festival in California, click here $\rightarrow$ web link.

1. Pinyin is "a system for writing Mandarin Chinese in Roman letters rather than Chinese characters" (Cambridge English Dictionary), which is particularly convenient for text entry on smartphones. School children and Chinese learners are often taught pinyin as a way to represent the phonetic sounds of the spoken language. They are later instructed on the traditional logographic writing system of Chinese. For example, "water" in Chinese can be annotated by toned pinyin as shul which reflects its proper pronunciation; "water" in Chinese can also be represented by the traditional logograph 水 which is the orthodox writing system in China. 


\section{$8=$}

\section{狗狗也冲浪? 还比赛! 加州更多精(sang)彩 (xin)有(bing)趣(kuang)的节日，来翟 $\rightarrow$ 网网页 链接}

Figure 1. Screen shot of a post from the official account of Californian Tourism Bureau on Sina Weibo ${ }^{2}$

As can be seen in Figure 1, phonetic transcriptions and Chinese characters occur together within one sentence. Such unexpected co-occurrence is likely to cause confusion especially when the transcriptions do not correspond to their neighboring Chinese characters' correct pronunciations. These pinyin symbols, although eye-catching, do not translate the exact pronunciations of their adjacent characters. The original and correct phonetic transcriptions of the characters 精 彩有趣 are jīngcǎi yǒuqù, meaning 'fascinating and interesting. Together with the photos from the web link, they send a message typical of an advertisement looking for attention. By alluding to the rhetoric of the prospective tourists (e.g. "The dog is surfing?"), the poster seems to invite the audience to construct a recreational frame in which "fascinating and interesting" would be the keynote of these activities. However, there is a twist. The adjacent pinyin symbols "(sang) (xin) (bing) (kuang)", ${ }^{3}$ when put together, mean "insane" and carry a negative connotation. In Chinese, this four-character idiom normally occurs in negatively connoted contexts such as criminal activities or immoralities. ${ }^{4}$ Thus, using "insane" to evaluate the photos of tourist attraction may trigger negative inferences. Even though negative evaluations could be interpreted as friendly banter (cf. Culpeper 2011) in certain contexts, they cannot be determined as such when used in a collapsed context where the social distance between the users may be as varied as the number of participants in that particular context.

The origin of such mismatched annotation practice is hard to trace. It seems that as early as 2008 when China hosted the Olympic Games in Beijing, Chinese netizens took a fancy to the 'Chinese character (pinyin)' construction in their online language use in response to the slogan publicized on the internet ‘北京欢迎您’ bě $i$ jīng huānyíng nín, meaning 'Welcome to Beijing. Their initial participation was but

2. See http://weibo.com/u/1880848577 (accessed 4 November 2016).

3. The absence of tones here is due largely to the technical limitation of input.

4. cf. Chinese online corpus at www.cncorpus.org (accessed 27 July 2019). 
to play by the rule - pinyin symbols deployed were accurate phonetic transcriptions of the adjacent Chinese characters. Over time, the accurate phonetic transcriptions that pinyin symbols are meant to represent evolved, and the structure 'Chinese character (annotation)' came into use instead, where the annotations took the form of either pinyin symbols or Chinese characters, denoting meanings apparently irrelevant to those conveyed by the Chinese characters. ${ }^{5}$ Language play like the one in Figure 1 was then adopted by many social media users. While there is ample evidence that social media users in other languages (e.g. French, Italian, Japanese) play with typography and orthography (e.g. Anis 2007; Herring and Zelenkauskaite 2009; Nishimura 2016), limited research of this kind has been done in Chinese (but see Lee 2007, 2014; Su 2007). Research on the particular linguistic behavior described in this paper is even rarer, in which pinyin under study serves more as an indication of the user's pragmatic interests than for informative purposes. The occurrence of its 'Chinese character (Chinese character)' variant suggests the vitality of this language play online and beckons for further study. This purposeful "leakage" (Gruber 2019a) of extra information in the form of annotation is an apparent invitation to the audience to reconstruct their mental image following the intention of the poster. The apparently irrelevant way of annotation ${ }^{6}$ in this discursive construction also runs contrary to the online communication practice which is often represented by syntactically reduced forms, abbreviations, and shorthand symbols especially in the situation of character-constrained mode. Folk explanations for this effortful creation of construction mainly revolve around the strict censorship (contents containing sensitive keywords are filtered and blocked). However, in our data the posts within which this construction situates show no clear connection with sensitive topics but verge more on the fun of language play. Therefore, in this study we want to address the following two questions concerning the 'Chinese character (annotation)' construction:

1. What are the general patterns of such language play?

2. Why do social media users engage in such language play?

The rest of the article is organized as follows. In Section 2 we elaborate on some theoretical considerations for the current research. Section 3 shows how the data have been collected and how we approach the data to arrive at the answers to

5. See "Phonetic annotation of Chinese Characters takes an entertainment-turn, with the internet witnessing an influx of phonetic wordplay” (汉字注音也成娱乐 网络开始“咬文嚼 字”). See http://it.sohu.com/20080731/n258511098.shtml (accessed 8 August 2016).

6. As pinyin is the phonetic transcription of an expression, it carries the semantic connotation of that expression. In this study, we presuppose the conventional connotation of each expression. 
the research questions. We also show some characteristics of the two major data sources and their implications for language style. In Section 3 we focus on the screen data to address research Question 1. In Section 4 we provide a pragmatic account of this way of communication through semi-structured interviews to address Question 2. In Section 5 we conclude our findings. Given the small size of the corpus of texts and interviews gathered for this study and its exploratory nature, we need to point out that we have no intention to come up with a major generalization of the language play under study. However, our triangulation design and thick reading of the data seem to be able to demonstrate social media users' creative bonding strategies across different platforms.

\section{Theoretical background}

We have mentioned in passing the concept of frame when discussing the mental image evoked by the words "fascinating and interesting" in Figure 1. From a linguistic perspective, a frame is evoked when an association of conventional understanding is established (Fillmore 1985). This concept has been applied in (im)politeness research in both the bottom-up (Kádár and House 2020) and the top-down way (Terkourafi 2001), ${ }^{7}$ explicating the conventions lurking in interaction, though some of them may have little to do with (im)politeness. In discourse analysis, the knowledge of conventional meanings as default values within a particular community triggers certain conceptualizations at both abstract (conventional) and specific (contextual) levels. When we link a linguistic form with a linguistic context, we may also inferentially activate a mental frame with predefined default values (Ziem 2014). The language play under study seems to manifest the poster's manipulation or employment of frame(s) in an ostensive way. The social action is generally to key (Goffman 1974) one frame into another for a certain desired effect. Back to Figure 1, the poster may have assumed an interactive frame representing people's prior experiences and expectations (Tannen and Wallat 1993) about the speech activities concerned. Yet, when designing and displaying the message, the poster may have an imagined audience in mind: the pinyin annotation implanted in the positive keynote-carrier construes a derogatory connotation towards what the poster has depicted in the post. Without direct contact with those language players, we can only speculate that the poster is somewhat teasing for emotional involvement (cf. Haugh 2017).

To chart a consistent categorization, we orient to the tone of the frame evoked as opposed to a particular frame. In other words, we use the label 'positive', 'neg-

7. We are grateful to one of the reviewers for pointing this out. 
ative' or 'neutral' to indicate different tones of frames evoked by the situated conventional meaning of the Chinese character construction at an abstract level, and will be specific with case analysis within each category at discourse level. The language play in Figure 1, for example, evokes a recreational frame and is of the "positive (negative) frame" pattern in terms of the tones each connotation carries, which is the major but not the only pattern that emerges from the data (more in Section 3). Such added layer of meaning can hardly be understood simply at a linguistic level, for a manifested negative evaluation may reveal doubts about social order and denial of accepted beliefs, values and/or norms. Also, other heterogeneous combinations of these three dimensions show that the motivation for such language play may not be restricted to the teasing effect only. We intend to tab into this aspect through direct contact with the users in question.

In the internet era, telling and/or sharing a story in social media is dramaturgical because the tellers often bring together poly-interpretable elements (cf. Page 2018). We assume that such language play is a kind of dramaturgical presentation in the sense that the annotation and the annotated represent two frames at play. As has been demonstrated in Figure 1, while the positively connoted characters may evoke a recreational frame for the official account's frontstage image, the negatively connoted pinyin symbols may only be reserved between intimates in a backstage talk. On the other hand, research applying Goffman's (1959) dramaturgical theory to the interpretation of self-presentation in English social media from various disciplines (e.g. psychology, sociolinguistics, philosophy and interpersonal communication; cf. Hogan 2010) seems to have established the consensus that in the internet era, the concepts of 'frontstage' and 'backstage' are relative ones, constantly in flux, and variable in social life. They can be tacitly manipulated to achieve a certain desired effect.

In a recent study (Maíz-Arévalo 2017), self-presentation is equated with selfdisclosure and is deemed as one of the macro-strategies for individuals to get "likes" in social media. Compared with presentations through photographs or other visual discourses, textual self-presentations tend to reveal information more explicitly about oneself (Maíz-Arévalo 2017, 577). Hogan (2010) argues that instead of focusing on the distinction between frontstage and backstage, we need to distinguish performance as ephemeral act from performance as recorded act when applying dramaturgical theory to social media exploration. For him asynchronized online performance may have "digital traces designed to signify the individual" (Hogan 2010, 380), thus self-presentation in social media is more like an exhibition aiming at "being found" apart from "being present and performing". We feel the concept of 'online community of practice' could be introduced in combination with dramaturgical theory to provide a useful lens for understanding 
the motivation behind such 'Chinese character (annotation)' language play across social media platforms.

Virtual ethnography research on online conversation has shown that the concept 'community of practice' (Lave and Wenger 1991; Wenger 1998) reflects how people can simultaneously belong to different groups. Such communities are characterized less by geographical proximity or relational histories than by group members' endeavors in creating mutually recognized social practices. The concept of online community of practice has recently been applied in the analysis of the constructs of people's (im)polite behaviors in online gaming (e.g. Graham 2018) and humorous activities (e.g. Dynel and Poppi 2019) within a particular group of communication. In our study, engaging in this typical language play parallels more to other virtual communities based on the deployment of hashtags (cf. Zappavigna 2014, 2018), because the participation crosses both physical and virtual community boundaries. Yet, unlike hashtag communities that generally have a shared topic of interest, this kind of community orients around a fun part of language which may result in a distinctive communicative value.

It's true that engaging in language play may be a conscious effort to win appreciation from other group members (North 2007), but the language play this paper focuses on seems to be capable of fostering a sense of social bonding among members across different online communities for a shared cultural interest (here the spell sound of standard Mandarin). Thus, the imagined community in social media (Marwick and boyd 2010; Tagg and Seargeant 2014; Dynel 2017) is a process whereby participants may be encouraged to produce and interpret similar discourses, forming 'virtual communities of practice. In this sense, the audience is constructed as much as targeted. As Wenger (1998, 83) argues, a community of practice "enters into the experience of participants through their very engagement".

For this study we want to add that through language play, the posters concerned are capable of navigating the potentially limitless audience for social bonding; in the meantime, they may write the community into being (see Section 3). Imagination as a sense of belonging can contribute to expanding the scope of reality and identity. By interviewing the users for their perception and sense of belonging to the imagined community they have created or 'naturally' formed by themselves, we may get an insight into why people across social media platforms would engage in such a language play.

All in all, the participatory culture that features Web 2.0 offers various framing potentials whereby users interact in dramaturgical activities for their imagined audience. As Zappavigna (2011) suggests, what deserves more academic attention is how users form the "ambient affiliation" in the non-reciprocal relational context, where the "follow" relation does not necessarily lead to direct interaction 
among the users (Zappavigna 2014). We feel that through the lens of frames, dramaturgical display, and online community of practice, we can trace the pragmatic functions behind the language play under study.

\section{Data compilation}

The current research draws on the tenet of computer-mediated discourse analysis (CMDA, Herring 2004) and the sociolinguistic approach to online data collection (Androutsopoulos 2013, 2015) that includes the blended ethnography in understanding media language.

\subsection{The collection of screen-based data}

The language play under study is restricted to written communication in the context of the Chinese speech community, which constitutes the screen-based data. They come from two different social media platforms, Sina Weibo (henceforth Weibo) and WeChat (including WeChat Moments and WeChat Subscriptions) for their privileged status in mainland China's social media, and for the recurrence of the target language play therein. Regarded as the Twitter of China, Weibo now prompts users to create constantly updated timelines (without a word limit) ranging from humor and musings on life to "breaking news" (Georgakopoulou 2017) and reposts from other users and/or from other platforms. It allows access through the web, smartphones and other devices that encourage instant posting of photos, on-the-spot reports and quick responses to/by others. Unless the privacy function is activated, one does not need to wait for the owner's approval to be a ratified follower.

WeChat is a "cross-platform service" featuring Chats, Moments, Subscriptions, WeChat Pay, etc. Though often compared to Facebook Messenger in the West, it seems more functional. Its Subscriptions allows private users to be officially registered, to send multimodal messages to subscribers and interact with them providing various services. It also allows keyword search by non-followers using its built-in search functionality. WeChat Moments (henceforth Moments), on the other hand, supports users' posting of images and texts, sharing articles or other multi-media snippets, as well as making comments and sending 'wows' to all the entries in their feeds. Like Subscriptions, it allows non-followers from the same chat group to view each other's moments as long as certain privacy settings

8. Information retrieved from Wikipedia at https://en.wikipedia.org/wiki/WeChat (accessed 6 September 2016). 
are not activated. The targeted texts chosen from WeChat for the current study cover both Subscriptions and Moments.

In a nutshell, all the three databases allow heterogeneous followers. Although relatively restricted in the case of Moments, a demographic diversity is not totally impossible given the poly-media environment (cf. Madianou and Miller 2012) where most if not all social media users are immersed. Besides, all the platforms allow their users to 'repost' through their own accounts.' Thus, it is virtually impossible for any Weibo or WeChat user to count the potential audience, let alone actual readers. The sense of context collaps $\mathrm{e}^{10}$ is applicable to the three databases.

The data collected consist of 60 posts containing the 'Chinese character (annotation)' construction ( 30 from Subscriptions, 10 from Moments, and 20 from Weibo) that represent different topics ranging from non-serious ranting and teasing to serious discussions and complaining, as well as various forms of advertisements. In accordance with CMDA, the data were analyzed qualitatively: ${ }^{11} \mathrm{We}$ manually went over all the data and found that the annotated Chinese characters embedded in these posts can be as short as chunks of two or more words, or as long as an independent clause. As a native speaker's knowledge of conventional meanings can be regarded as default values within that speech community, which may trigger certain conceptualizations at both abstract (conventional) and specific (contextual) levels (Ziem 2014), we made a preliminary attempt at categorizing every sample along the evaluative negative-neutral-positive continuum in terms of its conventional connotations within the particular context it occurs. For the present study this categorization can manifest how language players juxtapose two different frames of connotation to achieve a certain effect. Such a communicative act can be rather emotive in the sense that it is strategic and intentional,

9. The function "Sent to Chat" can be a form of "repost" in the sense that the pictures in one's post can be distributed among other (group of) users whom the original poster may not even know; if reposting of screengrabs is taken into account, then "repost" is unrestrictedly allowed.

10. This is a term developed by Marwick and boyd (2010) from Wesch's (2008) notion that an infinite number of contexts could collapse upon one another within social media. Social media users might be aware of the potential permanence and replicability of their message, which makes it a tricky issue for them to engage in the complex negotiations needed to vary identity presentation and manage impressions as they normally do in face-to-face communication. As such they tend to construct an "imagined" audience in mind while doing online communication (see also Page et al. 2014; Dynel 2017 and all the references therein).

11. For the sake of clarity, the screenshots consisting of texts and emojis are presented in the form of texts with corresponding translations. 
involving extra work of editing and depending heavily on inferences about the speaker's intention(s). ${ }^{12}$

\subsection{The user-based data}

The user-based data, collected for both etic and emic interpretations, consist of two sets. The first set reflects an intention to verify our conventional interpretations through 3 group interviews (Group 1: $N=4$, 2 female, 2 male; Group 2: $N=5$, 3 female, 2 male; Group 3: $N=5,2$ female, 3 male). They are active participants of the language play under study. We asked these interviewees to mark their agreement or disagreement individually with the samples in terms of emotive connotation rated before the group interview was conducted. Thus, each group would have 20 samples randomly picked from the data ${ }^{13}$ (more in Table 4 in Section 4 ). We briefed each group about what we meant by the terms 'positive', 'neutral', and 'negative', so their work was reduced to ticking in corresponding cells, as the following clip shows:

Table 1. Sample of interviewees' assessment for interview Phase 1

Disagreement

Example

Character Annotation Agreement \& suggestion

\section{加州旅游局 of}

14-8-7 17:26 来自微博 weibo.com

狗狗也冲浪? 还比赛! 加州更多精(sang)彩

(xin)有(bing)趣(kuang)的节日, 来翟 $\rightarrow$ 网页

链接

Positive Negative

In case they held doubts about our categorization, they were encouraged to suggest their interpretation about the examples given. Since the interviews were mainly for macro-level ideas instead of micro-level features, summative reports rather than transcriptions were taken in text form. These interviewees are regular social media users: they have registered on more than one social networking site and they generally spend more than 30 minutes in social media on a daily

12. Emotional communication, on the other hand, is often spontaneous and not necessarily intentional, and the major function is less communicative than helping the speaker maintain psychic balance. It is a manifestation of, not about state of affairs (cf. Arndt and Janney 1985, 1987, 1991).

13. Given the high inter-rater agreement and the interviewees' willingness of committed time, we only gave each example one-time assessment. With any disagreed-upon examples, which were very few, we categorized them into "Others" (See Table 4 in Section 4) 
basis. Although they now live and work in the same city, they grew up (till the age of 18) in different parts of China. They are also personal acquaintances of the researchers, whose retrospective accounts, together with the literature review and the researchers' introspection, are conducive to the design of a more targeted interview at the second phase. Each group interview lasted about 60 minutes. During the second phase, semi-structured interviews were carried out individually with different targeted subjects $(N=4,2$ female, 2 male): two from Weibo official accounts and two from WeChat Subscriptions. Each individual interview lasted around 50 minutes. They were selected for their primary double online roles (they are editors of official accounts and have personal accounts on the same platform) and for their willingness to participate in an in-depth interview. The following two tables give the general information about the subjects' background for the two-phased interview:

Table 2. Demographic features of the subjects in the interview (Phase 1)

Living place prior to age 18

\begin{tabular}{lccccc} 
Gender $^{*}$ & Age & Number & North East & Central & South East \\
\hline \multirow{2}{*}{ Male } & $25-35$ & 3 & 1 & 2 & 1 \\
& $35-45$ & 4 & 2 & 1 & 1 \\
\multirow{2}{*}{ Female } & $25-35$ & 3 & 1 & 1 & 1 \\
& $35-45$ & 4 & 1 & 2 & 1 \\
\hline
\end{tabular}

* Our subjects were explicit about their gender identity.

Table 3. Demographic features of the subjects in the interview (Phase 2)

Living place prior to age 18

\begin{tabular}{lccccc} 
Gender & Age & Number & North East & Central & South East \\
\hline \multirow{2}{*}{ Male } & $25-35$ & 1 & 1 & 0 & 0 \\
& $35-45$ & 1 & 0 & 1 & 0 \\
\multirow{2}{*}{ Female } & $25-35$ & 1 & 1 & 0 & 0 \\
& $35-45$ & 1 & 0 & 0 & 1 \\
\hline
\end{tabular}

Even with such a small sample of interview group, we have tried to diversify with every means the demographic backgrounds so as to avoid as much bias as possible. 


\section{The character (annotation) construction: Interpretation on screen- based data}

Androutsopoulos (2014) notes that language style in social networking is shaped by a tension between intimacy and publicness, or in Goffman's term, frontstage and backstage. That language play in question reflects such a tension was confirmed in the interview (all the interviewees agreed with all the evaluative frames we set for the examples except for 3, which were grouped under "Others" in Table 4). More than half of the annotations $(N=34)$ in the sample evoke frames that are at the negative end of a scale, as "insane" in Figure 1 shows. But such judgement alone would twist the reality if we fail to take into consideration the emotive communication in the process of keying. We group our data along the three emotive dimensions, namely, negative, neutral, and positive, and assume that the relation between the Chinese character and its annotation is positively oriented when the situated conventional connotation is either neutral or positive (see the analysis below). All the examples are thus categorized as Table 4 shows: ${ }^{14}$

Table 4. Evoked tones of frames in the language play

\begin{tabular}{|c|c|c|c|c|}
\hline & Characters & Annotations & Number & Total \\
\hline & \multirow[t]{3}{*}{ Positive } & Negative & 25 & 30 \\
\hline & & Positive & 5 & \\
\hline & & Neutral & / & \\
\hline & \multirow[t]{3}{*}{ Neutral } & Positive & 2 & 17 \\
\hline & & Negative & 7 & \\
\hline & & Neural & 8 & \\
\hline & \multirow[t]{3}{*}{ Negative } & Positive & 4 & 8 \\
\hline & & Negative & 2 & \\
\hline & & Neutral & 2 & \\
\hline Others & & & & 5 \\
\hline Total & & & & 60 \\
\hline
\end{tabular}

As statistics in the table demonstrate, the tone of the frame evoked by the Chinese characters is mostly non-negative $(N=47,30$ positive plus 17 neutral in the whole sample). Even within negatively-toned frames $(N=8)$ evoked, the users would key in a positive tone $(N=6,4$ positive plus 2 neutral). A close reading

14. The inter-ratio agreement reached $85 \%$ between two researchers in 2018 and after one-year interval, it reached 90\%. The undecided items are grouped under the label "Others". 
of the data reveals that in the lion's share of the non-negative communication $(N=30+17)$, the users are mostly doing teasing $(N=20)$ or further elaborating $(N=13)$ through annotations (see the analysis below). To explore the pragmatic effects behind this keying process, we focus on the cases that are more representative in the dataset (with the number being more than 2). The Positive-Negative pattern in Figure 1 shows that using the negatively-toned pinyin symbols (meaning 'insane') to annotate a 'fascinating' event is like keying a backstage talk into a frontstage performance. Whether such staged intimacy can generate desired economic return through tourist attraction goes beyond our research focus. In what follows we will show, by examining the mechanism of frame juxtaposition, that we can probe into the communicative performance behind such language play.

\subsection{Neutral-Neutral pattern}

Example 2. (from WeChat Subscription)

温馨提示：语言学午餐与本文提到的品牌没有合作关系，请广大食 (du) 客 (zhe) 放心享用。

Warm tips: There is not any kind of business cooperation between Ling-Lunch and the brand mentioned in the article. All the diners (the readers) please rest assured and enjoy yourselves.

This example is taken from a WeChat Subscription devoted to sharing juicy linguistic stories or language play in our everyday life. The annotated characters 食客, if translated correctly into their proper pronunciations, should be shikè, meaning 'diner'. Such an analogy comparing all the readers of their posts to diners works on two levels. First, it resonates with the Chinese formulae 以飨读者 y̌xiăngdúzhě 'to entertain the reader', often used in the editorial register, where the literal meaning for the character 飨 is "to treat the guest with food and wine". This metaphor also coincides with the English idiom 'food for thought', which is widely-known encyclopedic knowledge that can easily enact the metaphorical frame per se. Secondly, the analogy is situated within the frame of the structure metaphor (Lakoff and Johnson 1980, 14) evoked by the ID of the official account itself - "Ling-Lunch". If regular tweets of the posts at noon can be compared to serving lunch at their own account, it follows within this structure that readers who come to the subscription for fun are like diners who visit the place for lunch. The pinyin symbols "(du) (zhe)" embedded in the post, meaning "reader", are but the target domain of the metaphor. Both two terms are labels of social roles and convey neutral tones. Given the easily recognized metaphorical frame, it looks rather redundant for the poster to make an extra effort to key a literal frame through annotations. We can speculate from the screen-based data, later confirmed in the interview (Phase 1), that the poster was engaging in the trendy 
practice of 'Chinese character (annotation)' construction in social media. Even though the congruent tones of the two frames may not generate the dramatic effects as the example in Figure 1 does, the poster has at least established a membership of the virtual community produced by such practice of language play.

\subsection{Positive-Positive pattern}

Example 3. (from Weibo)

\#轰啪啦\#有内涵，有节操的《轰啪啦》在网易云音乐上线啦～还在 发愁寂寞的夜晚没人陪? @牛轰轰LZZ温 (hao) 婉 (mai) 动 (cu) 听 (kuang) 的声音哄你入睡

\#Hongpala\# Hongpala the broadcasting station of culture and principle is available now at NetEase Cloud Music Still feel lonely and unaccompanied at night? @NiuhonghongLZZ will lull you to sleep with a gentle and soothing (loud and rough) voice

In the post taken from Weibo, both the annotated characters 温婉动听 wènwăn dònting, meaning 'gentle and soothing', and the annotation pinyin symbols “(hao) (mai) (cu) (kuang)," meaning 'loud and rough', can be used to describe conventional but distinctive singing styles, and both would evoke different frames of appreciation. The keying of one positively-toned frame into another positivelytoned frame can somehow generate a humorous interpretation because the pinyin symbols positioned in the adjacent brackets give the positive evaluation an ironical touch: such move of innuendo combined with the broadcasting time ("at night") constitutes what Coulson (2001) terms 'counterfactual blending, for to go to sleep, even in daytime, would discount any loud and rough music as indicated by the pinyin annotation. This reading is verified by the features of the broadcasting station and the style of its host as well as the reading of other users interviewed in Phase 1. Through this example we can see that frames as specific schemata can be creatively manipulated in terms of both form and meaning, that the enactment of two frames through a keying process, regardless of the extent to which they share the similar positive tones, can still turn a frontstage into a backstage simply by following the practice of the community.

\subsection{Negative-Positive pattern}

Example 4. (from Moments)

昨天上的锁，今天就被捼了! 太 (干) 暴（得）力（漂）了 (亮)!

The lock installed yesterday was pried open today! That is too mobbish (well done)! ? 
In the example taken from a personal WeChat account, the annotated characters 太暴力了 tài bàoli le, 'too mobbish', would enact a negatively-toned frame in which we can easily picture the victim complaining about an unfortunate incident, a natural reaction in that particular context. The annotation characters 干 得漂亮 gànde piàoliàng, 'well done', on the other hand, would generate a conventional positively-toned frame of strong compliment. Yet, when keyed into a negative frame, i.e., the robbery in this example as set up by a short report of the incident, the illocutionary force of such compliment is more like a mockery. The Doraemon emoji at the end reinforces this reading, for Moments affords another more conventional emoji choice embodying the same emotive communication of "shock". Such conscious choice of impersonating a particular manga character (representing an adorable image of savior) increases the playfulness of the message. One more noticeable feature of this post is that the annotation takes the form of Chinese characters, plain and direct, making an alternative frame easier to access than pinyin symbols. Although later in the group interview the poster himself recalled that it was for the convenience of entering Chinese characters through mobile keyboards, he also mentioned that his "original response", indicated in the brackets, could be magnified in some way. In other words, social media users would view the pinyin symbols as metaphorically representing a comparative weaker voice, like a private murmuring in the public place. Once a form of communication takes on a conventional feature of usage, it is on the way of getting entrenched in that community.

\subsection{Neutral-Negative pattern}

Example 5. (from WeChat Subscription)

本来本人只想在知乎简单的回 (zhuang) 答 (bi), 没想到这么多妹子 加我微信。

I had thought only about contributing answers (faking to be some-

body) at Zhihu. It turns out unexpectedly that so many girls wanted to have my WeChat account.

This example is taken from a very popular official account of WeChat called Zhihu. ${ }^{15}$ The annotated Chinese characters 回答 huídá, 'contributing answers', is just a neutral statement of a past event conducted by the poster himself. The pinyin annotation (zhuangbi, meaning 'faking to be somebody') is a social-media-

15. Zhihu is a Chinese platform for users to ask questions and to have connections with people who may contribute unique insights and quality answers, like Quora in America. More information can be found from https://zh.wikipedia.org/wiki/\%E7\%9F\%A5\%E4\%B9\%8E (in Chinese, accessed 30 August 2019). 
born derogatory term deployed by the poster to do self-mockery, as well as showing his orientation to the virtual community discourse where self-denigrating humor is but a normal or ritual practice. This example demonstrates again that such language play of negatively-toned keying process has taken on the status of established practice within which members of the community start to explore less popular but no less conspicuous means of doing self-presentation. This keying process contributes to creating a humorous and witty image: he was explicitly boasting about his popularity with girls as well as his knowledgeable disposition, though in an apparently understating manner. Again, we find that the poster has been staging a backstage voice for the desired effect. Such manipulation sets the keynote for the upcoming narration and to a large extent reflects a genre of its own (cf. Gruber 2019b) worth further exploration: a lot of serious discussions and sharing of professional knowledge in social media are framed in a non-serious tone. 妹子 mèi-zi, 'younger sister' or simply 'girl', originally a dialect spoken in Northern China, is now often associated with the style of straightforwardness and humor. When migrated to social media, such term is applied far and wide among users despite their regional backgrounds and social identities. The very use of 妹 子 seems successful in conveying the poster's conscious effort to close his social and psychological distance with the audience, thus manifesting his social bonding awareness. We also notice that some users tend to use this 'Chinese character (annotation)' structure to do the orientation work for dialect perception as illustrated below.

\subsection{Dialect perception orientation}

Example 6. (from WeChat Moments)

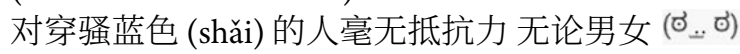

So vulnerable to those in coquettish blue ${ }^{\star}$ whatever their gender ${ }^{(}{ }_{-}$ఠ)

We admit that the translation has failed us and can only use asterisk “*” to indicate that the pinyin annotation in this example is closer to its prototypical function, i.e., to indicate the correct pronunciation of the adjacent character. However, in this case, an "appropriate" pronunciation might be more pertinent, for the pronunciation indicated by the pinyin only occurs in oral Chinese on informal occasions. Such extra effort to construe the intended sound image somehow keys in a perspective shift. The whole sentence reads more like an utterance from the poster. And together with the emoticon ${ }^{\left({ }_{-}{ }^{\circ}\right)}$ at the end indicating a sense of 'helplessness', these multi-semiotic symbols orchestrate such fun reading. With this particular case, we can sense that once the keying process has become an 
entrenched practice, the original function of pinyin can achieve a frontstage performance effect.

Through these cases we find that social media users are rather creative in making use of the keying processes even at a very abstract level along the positiveneutral-negative dimensions. Regardless of the particular frames evoked with specific expressions, such emotive communication can either foreground a backstage style or render a frontage into a backstage. It goes without saying that with a more nuanced categorization of dimensions and more data collected, we may make a more refined review of the art of framing in impression management in social media. Even with this small set of data, however, we already see the complexity of using conventional meanings of words to manipulate frames. Such simple division of frame tones along the positive-neutral-negative continuum would not necessarily lead to the corresponding emotive communication involved. As Examples (3) and (4) have demonstrated, through the process of keying, however positive or neutral the annotated and the annotation might be, the intended affective meaning would still be to make fun either of oneself, or of other people at large. Our preliminary observation shows that Chinese social media users are manifesting their communicative competence through this way of performance and their efforts can generate different pragmatic effects or goals, one of which may be to stage an alternative self to get liked by people sharing the same interest. And this is the issue to be addressed in the next section.

\section{Who is talking to whom: User-based data analysis}

As presented in the methodology section, our interviews were conducted in two phases. Phase 1 was more of a chit-chat with a group of acquaintances to corroborate our readings of the data (which have been integrated into screen-based data analysis and the sample survey in Table 1) and to get our perspective in designing a more focused interview for the targeted double-role users. We will present the planned question for Phase 2 in gist, for in real one-on-one talk, the whole process is livelier and more bubbling than the dry protocol listed. Given that adhering to a fixed agenda of questions may lead to an inflexibility that defeats the purpose of uncovering tacit as well as explicit knowledge (Boxer 1996), our semi-structured interview was designed to let the interviewees speak out in a more revealing way. Our findings are thus presented in the form of a general report substantiated with direct quotes when necessary. 


\subsection{Findings from Phase 1}

Drawing on the findings by previous research (Litt 2012; Jones 2015; Toma and Carlson 2015; Utz 2015; Georgalou 2017), we integrated the following points into our preliminary interview to corroborate our readings and to shape our more formal interview for the next phase:

- the impression of the users who resort to this type of language play;

- the possible reasons why this language play is gaining wider usage; and

- the effects generated by such language play.

Close relationships with the researchers encouraged the interviewees to be more open and share more than what the researchers would have expected, with more serendipitous information obtained. They are non-linguists themselves, and their feedbacks have contributed to the validity and pertinence of the interviews afterwards. In terms of the impressions towards these language players, we get the following mixed feedback: Females in their early 20 s $(N=4)$ thought this group of users must be linguistically competent and admirably socializing. However, certain males in their early $40 \mathrm{os}(N=2)$ believed this discursive construction to be very contrived, the users showy, the whole language play nothing but entertaining. And one of them remarked that

我可没时间去看这些女孩子家家的东西。

I'm too busy to appreciate these girly things.

This is a phenomenon that has been labeled infoxication (mental intoxication due to an excess of information to be processed, cf. Yus 2011). Social members are often multitaskers online and therefore "might develop a reluctance to devote cognitive resources to stimuli that do not offer immediate reward" (Yus 2011, 12). The gender-biased comment above somehow demonstrates that the practice is indeed community-based. These two interviewees were positioning themselves as outgroup members who do not appreciate contrived presentations despite the fact that our data also include examples created by male posters.

The possible reasons behind the wide usage of such language play may be associated with different statuses of the language players. When it comes to public accounts, these interviewees all agree, it is nothing but a strategy attempting more at appealing to a target group of audience in general than at presenting themselves in particular. They seem to be picking up the trend and entertaining themselves as well as the potential audience for fun. This point of view reflects the conceptualization of the imagined audience, who may be pulled and apprenticed into producing and interpreting similar discourses, bonding across different platforms in the virtual community of practice. 
As to the possible effects that language players can achieve through such social behavior, all of the subjects in Phase $1(N=14)$ agree that, playfulness aside, this can be a strategy of engaging the audience, displaying the social bonding effect of virtual community of practice as our study has shown.

\subsection{Findings from Phase 2}

Inspired by the findings from Phase 1 and in pursuit of the motivation behind this virtual community of practice, we intend to get answers directly from the targeted interviewees, i.e., the social media users who are owners of both official and personal accounts:

- How is the 'Chinese character (annotation)' construction created?

- To what extent does the 'character (annotation)' construction help achieve the desired pragmatic effects?

Unfortunately, none of the interviewees could give precise and definite principles that have guided their creative language play, but they suggested that the juxtaposition of the Chinese character and pinyin symbols could be a shift in perspective. Bracketed annotations may be just as true to the situation back there and, when things have happened, reveal their on-the-spot spur of thought. These annotations may also be a post-event creation to obtain a desired effect. The annotated instances are most often serious while the annotation ones (either Chinese characters or pinyin symbols) are teasing and sometimes self-deprecating, whatever the keying process looks like. These interviewed users felt it is not difficult for them to create texts that tickle through this form of expression. And they did not mind that this practice would demand more mental effort on the part of some readers. As one of the Subscription editors remarked in a teasing way:

\section{我感觉我的粉丝团都爱玩这个，他们也都这么玩，要是有人不喜欢这种游 戏，多半是因为他们年龄大了太out了，或者他们拼音没学好，哈哈。 \\ To my knowledge, our fans quite enjoy this kind of language play. A lot of them follow this suit. If certain people dislike this game, it is most probably because they are old and outdated, or they are not good at pinyin. Haha.}

This comment demonstrates, from an emic perspective, that individuals treat such language play as a way of drawing lines between different communities, showing that they are young and trendy. They bond through such semiotic play and attribute positive values to the community they co-create without much consideration of geographical or gender differences. On the other hand, they admitted that it is the popular structure that strike them first before the message is being composed. Internet technology affords great possibilities for these social media 
users to tap into part of themselves that may relatively be hard to realize in the physical world. As one interviewee added:

\section{就好比周围人已经对你有刻板印象了, 想尝试点不一样的别人觉得你遇到不 幸了}

It's like you have been stereotyped by those around you. If you try something different, they would think you must have experienced some misfortunes.

And they deemed it a safer way to deny the accepted values if it is done in a community where people are not from where they grew up. We can sense the balance these interviewees try to find between the sense of attachment to an in-group and the desire to draw a line between individual and institutional performance. And joining different virtual communities is what they deem the most efficient way to be an alternative self and get accepted easily.

As for the extent to which such language play can bring the desired digital attention, these users resonated with the fun from the language play and they saw their contribution as a way to mark their in-group identity and appeal to those who shared the same interests. Speaking from the role of an official account editor, one Weibo user noted,

曾经接到公众号的读者的留言，“小编原来也这样调皮”, 我觉得挺好

Once a subscriber left a message at my official account, commenting that "so the editor is just as naughty". I feel fine.

It seems that such linguistic behavior facilitates individuals to make alternative self-presentation under the guise of a professional role and get recognized by others from the same community of practice. This also supports the view that in social media people have a cognitive construction of their imagined audience and that the virtual community of practice boasts certain bonding power.

On the other hand, all the interviewed users emphasized that this internet language play is only one of the multiple ways to attract attention. The image quality, the text content, the typography and all the other layout techniques are what they might give more thought to than the 'Chinese character (annotation)' construction, manifesting the professional ethics an account owner shall adhere to within the double roles. All of these feedbacks lead to a follow-up question - why are those different voices put between brackets instead of being directly integrated into the text?

Interestingly, these users, who are strange to each other and who are in charge of different public accounts on different platforms, provided a similar response: If these annotations did not exist, there would be no desired effect, i.e., fun, from the sharp contrast between different representations. One of them noted: 
我们在括号内放入的不仅仅是我们自己的想法，抖包袱嘛。说实话，玩这个 的时候我们也没想到要在大家面前展现更好的自我。可能有心理暗示吧。

We are not simply putting our own thought into the brackets. That is how the punchline comes into being. To tell the truth, when we do this we are not thinking about revealing a better part of ourselves to our potential readers. There might be a psychological hint, though.

We may conclude that, for these language players, presenting an alternative self is not necessarily a means to an end in itself, though there might be a concern about the impression conveyed. The underlined part above shows that they care more about joining a group. The "psychological hint" may be their subconscious move in framing their selves into the accepted values of the community they feel they belong to.

\section{Discussion and conclusions}

Thurlow (2012, 170; italics in the original) remarks that "discursive creativity in new media is often poetic, usually playful and always pragmatic". In exploring the construction and pragmatic effects of particular language play in Chinese social media, this paper combines both screen-based data and user-based data in building up the interpretive context with respect to the particular language play and the value of a virtual community of practice in social media.

What we have found from the screen-based data is different from previous studies in Chinese CMC. The users do not play with code-switching or codemixing between different languages (Lee 2007, 2014; Su 2007), but with different ways of emotive communication within the same grammatical environment. When engaging in the 'Chinese character (annotation)' practice across different social media platforms, they can be very flexible and creative in deciding on the parts and the ways to be annotated. Keying through the juxtaposition of apparently irrelevant annotations and Chinese characters can not only generate fun but also establish or maintain community-related values. The assumption of avoiding censorship and maintaining social stability is not the concern among the users in our study. Rather, our subjects deemed it as one way to mark their community identity through such language play.

As Norrick (2004) points out, team performance and collaborative fantasy contribute to social bonding and rapport building. Our interview points to the fact that people do draw on the subcultural capital of community of practice to develop social bonding among themselves, despite the geographical difference and/or social distance; at the same time they manifest various attitudes and emotions embedded in the meta-structure, entertaining alternative, if not conflicting, 
identities in the process. The practice of framing their stories from different perspectives at the same time and thus animating alternative voices, not only induces a playful effect that facilitates social bonding across the collapsed context, but also helps to (re)contextualize shared cultural interests and community values. Individual users code their messages with an imagined audience in mind, disclosing an alternative self through this fun-seeking means to trade for group solidarity, and constantly shaping the virtual community they feel attached to. This seems to mirror Goffman's (1959) idea that whether for the potentially subconscious enhancement of community-related values or for the exploration of a less dominant but no-less critical part of themselves, people would always put on acts for other people to seek social bonds, even with people whose contexts may not necessarily be overlapping. And the blurring line of frontstage vs. backstage in social media serves as a resource for users to create selves for different communities where they can find the social bonding they feel comfortable with.

The fundamental cultural norms in China include respect for hierarchy, distinction between inside and outside relations, and perception of the 'powerful' and the 'powerless', which remain relatively constant and unchanged in historical and contemporary China (Pan and Kádár 2011). Yet, in the virtual world, any clues to these dimensions of interpersonal meaning are often intentionally manipulated, or are too hidden to be easily detected. It is worth examining whether social media users in China, when engaging in self-presentation, act more in line with human relations and memberships governed by cultural norms in a general sense, or simply follow suit in their spontaneously formed virtual communities. It also pays to deal with their ways of presenting alternative selves in dramaturgical display. Future studies involving multi-semiotic data and interactional discourse may further contribute to our understanding of interpersonal meanings in this mediated social life-world.

\section{Funding}

Research funded by National Planning Office of Philosophy and Social Science (12BYYo44) to Chaoqun Xie.

\section{References}

Androutsopoulos, Jannis. 2013. “Online Data Collection.” In Data Collection in Sociolinguistics: Methods and Applications, ed. by Christine Mallinson, Becky Childs, and Gerard Van Herk, 236-249. London: Routledge. 
Androutsopoulos, Jannis. 2014. "Languaging When Contexts Collapse: Audience Design in Social Networking." Discourse, Context \& Media 45: 62-73. https://doi.org/10.1016/j.dcm.2014.08.006

Androutsopoulos, Jannis. 2015. "Negotiating Authenticities in Mediatized Times." Discourse, Context \& Media 8: 74-77. https://doi.org/10.1016/j.dcm.2015.06.003

Anis, Jacques. 2007. “Neography: Unconventional Spelling in French SMS Text Messages.” In The Multilingual Internet: Language, Culture, and Communication Online, ed. by Brenda Danet, and Susan C. Herring, 87-115. Oxford: Oxford University Press. https://doi.org/10.1093/acprof:0so/9780195304794.003.0004

Arndt, Horst and Richard W. Janney. 1985. "Improving Emotive Communication: Verbal, Prosodic and Kinesics Conflict Avoidance Techniques." Per Linguam 1:21-30.

Arndt, Horst, and Richard W. Janney. 1987. InterGrammar: Towards an Integrative Model of Verbal, Prosodic and Kinesic Choices in Speech. Berlin: Mouton de Gruyter. https://doi.org/10.1515/9783110872910

Arndt, Horst, and Richard W. Janney. 1991. "Verbal, Prosodic, and Kinesic Emotive Contrasts in Speech.” Journal of Pragmatics 15: 521-549. https://doi.org/10.1016/0378-2166(91)90110-J

Bell, Nancy (ed.). 2017. Multiple Perspectives on Language Play. Berlin: Mouton de Gruyter.

Coulson, S. 2001. Semantic Leaps: Frame-Shifting and Conceptual Blending in Meaning Construction. Cambridge: Cambridge University Press. https://doi.org/10.1017/CBO9780511551352

Culpeper, Jonathan. 2011. Impoliteness: Using Language to Cause Offence. Cambridge: Cambridge University Press. https://doi.org/10.1017/CBO9780511975752

Dynel, Marta. 2017. “Participation as Audience Design.” In Pragmatics of Social Media, ed. by Christian R. Hoffmann, and Wolfram Bublitz, 61-82. Berlin: Mouton de Gruyter. https://doi.org/10.1515/9783110431070-003

Dynel, Martal, and Fabio I.M. Poppi. 2019. "Risum teneatis, amici?: The Socio-Pragmatics of RoastMe Humor." Journal of Pragmatics 139: 1-21. https://doi.org/10.1016/j.pragma.2018.10.010

Fillmore, Charles J. 1985. "Frames and the Semantics of Understanding." Quaderni di Semantica 6(2): 222-254.

Georgakopoulou, Alexandra. 2017. “'Whose Context Collapse?': Ethical Clashes in the Study of Language and Social Media in Context." Applied Linguistics Review 8(2-3): 169-189. https://doi.org/10.1515/applirev-2016-1034

Georgalou, Mariza. 2017. Discourse and Identity on Facebook: How We Use Language and Multimodal Texts to Present Identity Online. London: Bloomsbury.

Goffman, Erving. 1959. The Presentation of Self in Everyday Life. New York: Anchor Books.

Goffman, Erving. 1974. Frame Analysis: An Essay on the Organization of Experience. Boston: Northeastern University Press.

Graham, Sage Lambert. 2018. “Impoliteness and the Moral Order in Online Gaming.” Internet Pragmatics 1(2): 303-328. https://doi.org/10.1075/ip.00014.lam

Gruber, Helmut. 2019a. “Are Austrian Presidential Candidates Ordinary People? Candidates' Self-Presentation Strategies on Twitter during the 2016 Austrian Presidential Election Campaign." In The Construction of 'Ordinariness' across Media Genres, ed. by Anita Fetzer, and Elda Weizman, 21-50. Amsterdam: John Benjamins. https://doi.org/10.1075/pbns.307.02gru 
Gruber, Helmut. 2019b. “Genres, Media, and recontexualization Practices: Re-considering Basic Concepts of Genre Theory in the Age of Social Media." Internet Pragmatics 2(1): 55-83. https://doi.org/10.1075/ip.00023.gru

Haugh, Michael. 2017. “Teasing." In The Routledge Handbook of Language and Humor, ed. by Salvartore Attardo, 204-218. New York: Routledge. https://doi.org/10.4324/9781315731162-15

Herring, Susan C. 2004. "Computer-Mediated Discourse Analysis: An Approach to Researching Online Behavior." In Designing for Virtual Communities in the Service of Learning, ed. by Sasha A. Barab, Rob Kling, and James H. Gray, 338-376. Cambridge: Cambridge University Press. https://doi.org/10.1017/CBO9780511805080.016

Herring, Susan C., and Astsa Zelenkauskaite. 2009. "Symbolic Capital in a Virtual Heterosexual Market: Abbreviation and Insertion in Italian iTV SMS.” Written Communication 26(1): 5-31. https://doi.org/10.1177/0741088308327911

Hogan, Bernie. 2010. "The Presentation of Self in the Age of Social Media: Distinguishing Performances and Exhibitions Online." Bulletin of Science, Technology and Society 30 : 377-386. https://doi.org/10.1177/0270467610385893

Jones, Rodney H. 2015. "Discourse, Cybernetics, and the Entextualisation of the Self." In Discourse and Digital Practices: Doing Discourse Analysis in the Digital Age, ed. by Rodney H. Jones, Alice Chik, and Christoph A. Hafner, 28-47. Abingdon: Routledge. https://doi.org/10.4324/9781315726465

Kádár, Dániel Z., and Juliane House. 2020. "Ritual Frames: A Contrastive Pragmatic Approach.” Pragmatics 30(1): 142-168. https://doi.org/10.1075/prag.19018.kad

Kirshenblatt-Gimblett, Barbara, and Sherzer, Joel. 1976. "Introduction.” In Speech Play: Research and Resources for Studying Linguistic Creativity, ed. by

Barbara Kirshenblatt-Gimblett, 1-16. Pennsylvania: University of Pennsylvania Press. https://doi.org/10.9783/9781512803150-002

Knospe, Sebastian, Alexander Onysko, and Maik Goth (eds.). 2016. Crossing Languages to Play with Words: Multidisciplinary Perspectives. Berlin: Mouton de Gruyter. https://doi.org/10.1515/9783110465600

Lakoff, George, and Mark Johnson. 1980. Metaphors We Live By. Chicago: University of Chicago Press.

Lave, Jean, and Etienne Wenger. 1991. Situated Learning: Legitimate Peripheral Participation. Cambridge: Cambridge University Press. https://doi.org/10.1017/CBO9780511815355

Lee, Carmen. 2007. "Linguistic Features of Email and ICQ Instant Messaging in Hong Kong." In The Multilingual Internet. Language, Culture and Communication Online, ed. by Brenda Danet, and Susan C. Herring, 184-208. New York: Oxford University Press. https://doi.org/10.1093/acprof:0so/9780195304794.003.0008

Lee, Carmen. 2014. "Language Choice and Self-presentation in Social Media: The Case of University Students in Hong Kong." In The Language of Social Media: Identity and Community on the Internet, ed. by Philip Seargeant, and Caroline Tagg, 91-111. Basingstoke: Palgrave Macmillan. https://doi.org/10.1057/9781137029317_5

Litt, Eden. 2012. “Knock, Knock. Who's There? The Imagined Audience.” Journal of Broadcasting \& Electronic Media 56(3): 330-345. https://doi.org/10.1080/08838151.2012.705195

Madianou, Mirca, and Daniel Miller. 2012. Migration and New Media: Transnational Families and Polymedia. Abingdon: Routledge. 
Maíz Arévalo, Carmen. 2017. “Getting 'Liked’” In Pragmatics of Social Media, ed. by Christian. R. Hoffmann, and Wolfram Bublitz, 575-606. Berlin: Mouton de Gruyter. https://doi.org/10.1515/9783110431070-021

Marwick, Alice E., and Danah boyd. 2010. "I Tweet Honestly, I Tweet Passionately: Twitter Users, Con text Collapse, and the Imagined Audience." New Media \& Society 13: 96-113.

Nishimura, Yukiko. 2016. "Style, Creativity and Play." In The Routledge Handbook of Language and Digital Communication, ed. by Alexandra Georgakopoulou, and Tereza Spilioti, 103-116. Abingdon: Routledge.

Norrick, Neal R. 2004. "Humor, Tellability and Conarration in Conversation." Text 24: 79-111. https://doi.org/10.1515/text.2004.005

North, Sarah. 2007. “'The Voices, the Voices': Creativity in Online Conversation.” Applied Linguistics 28(4): 538-555. https://doi.org/10.1093/applin/ammo42

Page, Ruth. 2018. Narrative Online: Shared Stories in Social Media. Cambridge: Cambridge University Press. https://doi.org/10.1017/9781316492390

Page, Ruth, David Barton, Johann W. Unger, and Michele Zappavigna. 2014. Researching Language and Social Media. New York: Routledge. https://doi.org/10.4324/9781315771786

Pan, Yuling, and Dániel Z. Kádár. 2011. Politeness in Historical and Contemporary Chinese. London: Bloomsbury.

Seargeant, Philip, and Caroline Tagg (eds.). 2014. The Language of Social Media: Identity and Community on the Internet. Basingstoke: Palgrave Macmillan. https://doi.org/10.1057/9781137029317

$\mathrm{Su}$, His-Yao. 2007. "The Mutilingual and Multiorthographic Taiwan-Based Internet: Creative Uses of Writing Systems on College-affiliated BBSs.” In The Multilingual Internet: Language, Culture and Communication Online, ed. by Brenda Danet, and Susan C. Herring, 64-86. New York: Oxford University Press. https://doi.org/10.1093/acprof:0so/9780195304794.003.0003

Tagg, Caroline, and Philip Seargeant. 2014. "Audience Design and Language Choice in the Construction and Maintenance of Translocal Communities on Social Network Sites." In The Language of Social Media: Identity and Community on the Internet, ed. by Philip Seargeant, and Caroline Tagg, 161-185. Basingstoke: Palgrave Macmillan. https://doi.org/10.1057/9781137029317_8

Tannen, Deborah, and Cynthia Wallat. 1993. "Interactive Frames and Knowledge Schemas in Interaction: Examples from a Medical Examination in Interview.” In Framing in Discourse, ed. by Deborah Tannen, 57-113. Oxford: Oxford University Press.

Terkourafi, Marina. 2001. "Politeness in Cypriot Greek: A Frame-Based Approach." PhD dissertation, University of Cambridge. Available online at: www.ideals.illinois.edu/handle /2142/9573 (accessed 3 March 2016).

Thaler, Verena. 2016. "Varieties of Wordplay." In Crossing Languages to Play with Words: Multidisciplinary Perspectives, ed. by Sebastian Knospe, Alexander Onysko, and Maik Goth. 47-68. Berlin: Mouton de Gruyter. https://doi.org/10.1515/9783110465600-003

Thurlow, Crispin. 2012. "Determined Creativity: Language Play in New Media." In Discourse and Creativity, ed. by Rodney Jones, 169-190. Harkow: Pearson.

Toma, Catalina L., and Cassandra L. Carlson. 2015. "How Do Facebook Users Believe They Come across in Their Profiles?: A Meta-Perception Approach to Investigating Facebook Self-Presentation." Communication Research Reports 32(1): 93-101.

https://doi.org/10.1080/08824096.2014.990557 
Utz, Sonja. 2015. "The Function of Self-Disclosure on Social Network Sites; Not Only Intimate, but also Positive and Entertaining Self-Disclosure Increase the Feelings of Connection." Computers in Human Behavior 45: 1-10. https://doi.org/10.1016/j.chb.2014.11.076

Wenger, Etienne. 1998. Communities of Practice. Cambridge: Cambridge University Press. https://doi.org/10.1017/CBO9780511803932

Wesch, Mike. 2008. “Context Collapse." http://mediatedcultures.net/projects/youtube/context -collapse (accessed 20 June 2016).

Yus, Francisco. 2011. Cyberpragmatics: Internet-Mediated Communication in Context. Amsterdam: John Benjamins. https://doi.org/10.1075/pbns.213

Zappavigna, Michele. 2011. “Ambient Affiliation: A Linguistic Perspective on Twitter." New Media Society 13(5): 788-806. https://doi.org/10.1177/1461444810385097

Zappavigna, Michele. 2014. "CoffeeTweets: Bonding around the Been on Twitter." In The Language of Social Media: Identity and Community on the Internet, ed. by.

Philip Seargeant, and Caroline Tagg, 139-160. Basingstoke: Palgrave Macmillan. https://doi.org/10.1057/9781137029317_7

Zappavigna, Michele. 2018. Searchable Talk: Hashtags and Social Media Metadiscourse. London: Bloomsbury.

Ziem, Alexander. 2014. Frames of Understanding in Text and Discourse. Amsterdam: John Benjamins. https://doi.org/10.1075/hcp.48

\section{Address for correspondence}

\section{Ying Tong}

School of Foreign Languages

Nanjing Xiaozhuang University

\#3601 Hongjing Avenue

211171 Nanjing, Jiangsu

China

ketytong@me.com

\section{Biographical notes}

Chaoqun Xie is a professor at Zhejiang International Studies University, China. He is currently interested in research on internet pragmatics and (im)politeness in internet-mediated interaction in particular. His recent publications include an edited volume titled (Im)politeness and Moral Order in Online Interactions (John Benjamins, 2020), originally published as special issue of Internet Pragmatics 1:2 (2018). He is Co-Editor-in-Chief of the journal Internet Pragmatics (John Benjamins) and Editor-in-Chief of the book series Advances in (Im)politeness Studies (Springer).

Ying Tong is a doctoral student at Fujian Normal University. She also teaches in Nanjing Xiaozhuang University. Her research interests cover (im)politeness, (multimodal) discourse analysis, and interpersonal communication in social media. 
Francisco Yus teaches pragmatics at the University of Alicante, Spain. He has specialised in the application of pragmatics (especially relevance theory) to media discourses and conversational issues. His main current research is focussed on a cognitive pragmatics approach to Internet-mediated communication (Ciberpragmática, Ariel, 2001; Ciberpragmática 2.o, Ariel, 2010; Cyberpragmatics, John Benjamins, 2011). Latest research also has to do with the application of relevance theory to the production and interpretation of humorous discourses (Humour and Relevance, John Benjamins, 2016). He is currently the Head of the Inter-university Institute of Applied Modern Languages of the Valencian Community (IULMA) at the University of Alicante, as well as Head of the Research Group "Professional and Academic English" at the University of Alicante.

\section{Publication history}

Date received: 15 March 2019

Date accepted: 15 April 2020

Published online: 24 July 2020 